"These women were proof that

'people power' is capable of

great things." Sue Nelson, page 36

the idea for an experiment, and then - on the basis merely of the hopeful presumption of its possible outcome - invest time and resources in funding and executing it in the anticipation of a meaningful result.

Work supported by the Templeton Foundation that investigates the relationship between science and faith could help to improve science communication and to address science-and-society issues. So let's hope that Templeton's son has the same penchant for meaningfully verifiable results as his dad.

Jonathan Cowie Thurnby Lodge, Leicester LE5 2WG, UK http://www.science-com. concatenation.org

\section{Vavilov's vision for genetics was among Stalin's many victims}

SIR - Jan Witkowski's review of Peter Pringle's fascinating and timely book on the famous geneticist Nikolai Vavilov ('Stalin's war on genetic science' Nature 454, 577-579; 2008)

is informative, but contains some oversimplifications and inaccuracies.

The review pays little credit to Vavilov as a unique theoretician, not just a practitioner of applied science. His intentions were not simply to feed the people or to cultivate sturdy mountain plants. His was a grander vision, worthy of his teacher William Bateson: to bring modern genetics into agriculture, to collect global data on his famous "homological series [parallelisms] in hereditary variation" and cultural plant centres of origin, and to compile global gene collections.

Because of the fraudulent geneticist Trofim Lysenko, a giant system of data falsification developed in the USSR. The subjects were forced to praise the emperor's new clothes where there were none. The relationship between Lysenko and Vavilov was indeed complicated: Vavilov first promoted Lysenko's vernalization experiments and his career. The totalitarian and unpredictable nature of Stalin's regime not only prevented free criticism of Lysenko's data and his primitive 'Soviet genetics', it also led to the destruction of critics and opponents. Biology was a front line in the ideological war waged against Western ('bourgeois') science.

To call Stalin's agricultural collectivization policy a "consolidation of land and labour" is an awful understatement: an estimated 10 million productive peasants and their families were exiled or imprisoned from 19291933. Stalin was hardly "desperate to feed thousands of citizens dying of starvation" when these were the same people he starved and murdered while sending Russian grain abroad.

No free discussion about "the best data available" was possible for scientists in 1930s Russia. Saying that "even now, politics continues to trump good science" should not be taken as equating murderous dictators with democratic governments. Victor Fet Department of Biological Sciences, Marshall University, Huntington, West Virginia 25755, USA e-mail:fet@marshall.edu

Michael D. Golubovsky Department of Molecular and Cell Biology, University of California-Berkeley, Berkeley, California 94720, USA

\section{Message from the heavens may be that there is no message}

SIR - In his Opinion piece 'Message from the heavens' (Nature 453, 1185; 2008), Martin Kemp tries to discern the meaning behind Maurizio Cattelan's shocking sculpture of Pope John Paul II felled by a meteorite. Although acknowledging that this sculpture has much in common with Marcel Duchamp's anti-art he proceeds to provide a range of possible interpretations that include seeing it as an allegory of the conflict between Darwinists and those with spiritual beliefs.

As the artist himself has chosen to remain silent on the topic (maybe wisely so), perhaps one should view this kind of art as a successful attempt simply to attract attention. Attention is such an important resource that people (scientists included) are willing to forsake financial gain to secure it. From this perspective, Cattelan's work fits an artistic tradition exemplified by people like Duchamp and Andy Warhol: masters at putting together pieces whose sole purpose was to grab our attention.

In a world increasingly awash with 'content creators' and the alltoo-human limited attention we can devote to them, I see this work as a superb attempt to generate novelty and shock - to make us sit up and concentrate, even if only fleetingly.

Bernardo A. Huberman Social

Computing Lab, HP Laboratories, 1501

Page Mill Road MS 1139, Palo Alto,

California 94304, USA

e-mail: bernardo.huberman@hp.com

\section{Senior staff of Mexican institute speak up}

SIR - We find that your News story 'Scientists rally to Mexican researchers' plea' (Nature 454, $143 ; 2008$ ) is unjustifiably biased in favour of Harold Kroto and the research group of the Terrones brothers whom he defends.

Our institute for scientific and technological research, IPICYT, is one of 27 nationwide research centres coordinated by Mexico's national council of science and technology (CONACYT). This relies on long-established mechanisms for selecting the best researchers and directors. The present director of IPICYT, David Rios Jara, is supported by all the other CONACYT directors and by different Mexican academic organizations in his stand on the Terrones brothers affair.

IPICYT comprises five highly successful multidisciplinary divisions and the national supercomputing centre, which between them operate four prestigious graduate programmes. The advanced-materials department (AMD) where the Terrones work represents about $20 \%$ of IPICYT's academic output.

The conflict involving the Terrones brothers attracted international attention because of their scientific reputation and connections with foreign scientists. These would not have been possible without the exceptional treatment and financial support they received at the hands of the former and current IPICYT directors. The AMD researchers, students, postdocs and technicians continue to work normally, despite the Terrones' claim that their group is being harassed and thwarted. The group remains the most well supported at IPICYT.

In relieving Humberto Terrones of his administrative duties, after more than seven years as AMD's head, Rios Jara was not persecuting him but was simply complying with the recommendation by the last external evaluating committee and the CONACYT governing board. One intention in removing these duties was to improve relations between the Terrones group and the rest of the AMD.

Mexican science is definitely not under threat, neither will it be affected by changing a single division head of a CONACYT centre. Indeed, the new measures enable the Terrones to enjoy more time on their research, which should help to boost their scientific output.

Carlos Barajas-López and senior staff members` Instituto Potosino de Investigación Científica y Tecnológica (IPICYT), Camino a la Presa San José 2055, Col. Lomas 4a. Secc. SLP, CP78216, México e-mail: cbarajas@ipicyt.edu.mx *See supplementary information for full author list

Contributions may be submitted tocorrespondence@nature.com. 